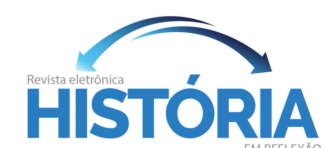

ESTRADA DE RODAGEM SÃO PAULO-BELO HORIZONTE: FLUXOS QUE CONSTROEM UM NOVO TEMPO SOCIAL EM “A VOLTA DO MARIDO PRÓDIGO” DE GUIMARÃES ROSA

Ana Maria Nogueira Rezende \& Maria Luiza Almeida Cunha de Castro

\title{
ESTRADA DE RODAGEM SÃO PAULO-BELO HORIZONTE: FLUXOS QUE CONSTROEM UM NOVO TEMPO SOCIAL EM “A VOLTA DO MARIDO PRÓDIGO” DE GUIMARÃES ROSA
}

\section{THE ROAD SÃO PAULO- BELO HORIZONTE: FLOWS THAT BUILD A NEW SENSE OF SOCIAL TIME IN "THE RETURN OF THE PRODIGAL HUSBAND" BY GUIMARÃES ROSA}

\author{
Ana Maria Nogueira Rezende ${ }^{1}$ \\ Maria Luiza Almeida Cunha de Castro ${ }^{2}$
}

\begin{abstract}
Resumo:Ao longo do período de colonização e até o início do século $X X$ na região das minas no Brasil, houve uma dupla articulação de fluxos, que gerou especificidades na organização econômica e social: a ligação com as vias inter-regionais movimentou uma economia exportadora, enquanto, na região, organizou-se uma economia de abastecimento, por meio de uma rede de caminhos regionais e vicinais. O conto de Guimarães Rosa descreve o momento da transição, no qual esta estrutura duplamente articulada estava prestes a ser rompida: a construção da estrada entre São Paulo e Belo Horizonte significa, não apenas a ligação entre os dois importantes centros, mas anuncia, por onde passa, uma transformação no sertão e sua incorporação aos fluxos inter e extra regionais, dentro de uma dinâmica de globalização.
\end{abstract}

Palavras-chave: Estradas, Sertão, Guimarães Rosa.

\begin{abstract}
Over the period of colonization until the beginning of the XXth Century there was a double articulation of flows in the region of Minas, in Brazil, which generated specific traits in the economic and social organization: the connection with the interregional routes supported the exportation of commodities (at first, gold and other minerals; afterwards, coffee), while a network of regional and local roads allowed for the supply of agricultural products within the region itself. Guimarães Rosa's short story describes the moment of transition in which this double articulated structure was about to be broken: the construction of the road between São Paulo and Belo Horizonte means not only the establishment of a connection between two major centers - but also announces the end of the backwoods isolation and their incorporation into the inter and extra-regional flows, within the dynamics of globalization.
\end{abstract}

\footnotetext{
${ }^{1}$ Historiadora pela Fundação Universidade de Itaúna; Mestre em Ambiente Construído e Patrimônio Sustentável pela Universidade Federal de Minas Gerais. E-mail: anitarezende@gmail.com.

2 Doutora em Ciências Socio-ambientais pelo Núcleo de Altos Estudos da Amazônia. Professora Adjunta da Escola de Arquitetura UFMG. Professora Permanente do Programa de pós-graduação em Ambiente Construído e Patrimônio Sustentável UFMG. E-mail: luizadecastro@ufmg.br
} 


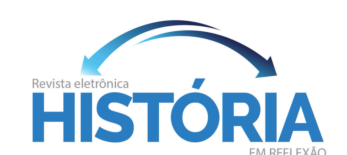

ESTRADA DE RODAGEM SÃO PAULO-BELO HORIZONTE: FLUXOS QUE CONSTROEM UM NOVO TEMPO SOCIAL EM “A VOLTA DO MARIDO PRÓDIGO” DE GUIMARÃES ROSA Ana Maria Nogueira Rezende \& Maria Luiza Almeida Cunha de Castro

Keywords: Roads, Backwoods, Guimarães Rosa.

\section{Introdução}

De acordo com Ricoeur (2010), o discurso histórico é quase uma narrativa de ficção. Embora o primeiro revele um tempo estrutural e a segunda, um tempo vivido, ambos pertencem à ordem das narrativas, que incorpora pontos de vista e escolhas especificas em detrimento de outras. A narrativa literária revela, assim, diversas dimensões da realidade e da sociedade, compondo o quadro histórico de cada época - desvendando por meio do imaginário, não só o mundo racional, mas também o mundo sensível (PESAVENTO, 2006)

A literatura de Guimarães Rosa é exemplar neste sentido. A obra do autor é interpretada sob duas perspectivas principais: uma visão atemporal, dentro da qual os personagens representam tipos e não necessariamente indivíduos, constituindo uma trama com desígnios universalizantes - "o sertão é o mundo" (CANDIDO, 2000? apud MAIA, 2007); e uma visão mais histórico-social, que revela nas entrelinhas as especificidades de uma época e suas relações sociais, além de trazer as bases e as peculiaridades de uma identidade sertaneja. Assim, ele coloca em cena a dialética entre o "arcaico e o moderno", "o regionalismo e universalismo"; (MAIA, 2007,s.p.), "cultura e rusticidade"; "civilização e barbárie" (RONCARI, 2004, p. 21).

Um dos aspectos frequentemente colocado em cena pelo autor são as estradas e caminhos que se alternam, ora como pano de fundo, ora quase que como protagonistas de suas narrativas. Eles aparecem, então, como importantes canais para veicular ideias novas que se infiltravam no sertão por ele retratado, na medida em que os lugares iam sofrendo influências de um tempo que os reconstruía.

$\mathrm{Na}$ região sudeste do Brasil, os caminhos e, mais tarde, as estradas, foram fundamentais para o nascimento, mas, também, para o desenvolvimento das cidades, pois concentravam fluxos, permitindo a consolidação da sociedade e da cultura. As características destes fluxos foram, portanto, determinantes para o caráter do povoamento e para o surgimento das identidades de cada lugar.

O conto "A volta do marido pródigo" tem como cenário a implantação da estrada que ligaria Belo Horizonte a São Paulo, materializando uma conexão direta entre duas regiões as quais, desde a época colonial, já se articulavam de formas tangíveis e 


\section{HISTÓRIA}

ESTRADA DE RODAGEM SÃO PAULO-BELO HORIZONTE: FLUXOS QUE CONSTROEM UM NOVO TEMPO SOCIAL EM “A VOLTA DO MARIDO PRÓDIGO” DE GUIMARÃES ROSA Ana Maria Nogueira Rezende \& Maria Luiza Almeida Cunha de Castro

intangíveis. A perspectiva é tomada a partir de Itaguara, cidade em que Rosa atuou como médico no início de sua carreira, na ocasião em que a rodovia estava sendo construída.

Em uma época em que os burros e mulas ainda eram responsáveis por uma grande parte das idas e vindas na região, o transporte ferroviário - cuja viabilidade econômica já era questionada, devido a seu alto custo - e o transporte rodoviário ainda incipiente - criavam uma nova rede que se infiltrava e se entrelaçava pelo interior, promovendo o que Appadurai (2004) denomina "disjunturas", este descompasso que surge da dinâmica entre o novo - que avança em alguns aspectos da vida - e o tradicional - que ainda se mantém arraigado, em outros.

O conto em questão, escrito em 1937, faz parte da obra Sagarana e apresenta o sertão em suas "diferentes temporalidades e espaços culturais". O título da coletânea sugere que as narrativas devem ser lidas "como se fossem sagas" revelando diferentes sentidos para as histórias contadas (MACHADO, 1998, p. 39). Suas narrativas apresentam características socio-históricas da sociedade do sertão, mas também aspectos simbólicos, potencializados pela riqueza da linguagem que o autor explora, cheia de imagens e neologismos, buscando a "expressividade na própria palavra ou no enunciado por meio da palavra” (LEONEL, 1997, p. 80)

Este artigo procura, então, dotar a perspectiva histórica de um novo contexto, analisando o processo pelo qual os caminhos foram sendo traçados, a partir de duas escalas de articulação diferentes, que colocaram o local sob uma tensão contínua: uma destas escalas, fruto da interligação dos núcleos de povoamento dentro da própria região, fazia com que eles se desenvolvessem em torno de suas especificidades; a outra, operando em eixos ampliados, buscava inseri-los nos fluxos do comércio nacional e internacional. Estes fluxos, polarizados na região pelo sertão e por São Paulo, culminaram com a construção da estrada, que enquadra o conto.

As técnicas de pesquisa utilizadas incluíram desde o levantamento de artigos até a investigação de documentos históricos municipais, textos e fotografias. A partir dos dados obtidos, foi feita a análise da pertinência das informações trazidas pelo

\footnotetext{
${ }^{3}$ Etimologicamente, Saga, de raiz germânica, diz respeito às narrativas em prosa, históricas e/ou lendárias, ricas em incidentes; e, rana, sufixo tupi, significa "à semelhança de", "ao modo de". (Nascimento, 2010 p. 20)
} 


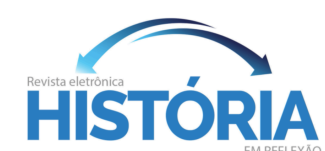

ESTRADA DE RODAGEM SÃO PAULO-BELO HORIZONTE: FLUXOS QUE CONSTROEM UM NOVO TEMPO SOCIAL EM “A VOLTA DO MARIDO PRÓDIGO” DE GUIMARÃES ROSA Ana Maria Nogueira Rezende \& Maria Luiza Almeida Cunha de Castro

conto dentro do contexto estudado. A estrada, que passa por Itaguara, anuncia, assim, uma perturbação da ordem estabelecida, que vai transformar as relações na dialética entre o lugar e o tempo. Sua implantação altera irreversivelmente a identidade construída dentro de uma dinâmica de fluxos regionais.

Estradas entre São Paulo e Minas e a articulação de fluxos locais e globais

A capitania de São Paulo e Minas do Ouro foi inicialmente desmembrada da capitania do Rio de Janeiro em 1706 e, em seguida, em 1720, separada em duas capitanias distintas (CRUZ, 2008). As rotas que partiam da cidade de São Paulo para a região mineradora interiorana, também conhecida por Minas dos Cataguases (MONTE-MÓR, 2001) passavam pelo sul da Capitania de Minas. Moraes (2005, apud CRUZ, 2008) identifica as três mais utilizadas: - além do Caminho de São Paulo ou Caminho Velho, havia aquelas conhecidas respectivamente como Caminho de Fernão Dias; e Caminho do Guaianazes.

Em paralelo a estas vias que faziam a ligação inter-regional, havia uma malha de rotas menores que fazia a articulação regional e vicinal, configurava uma identidade própria e fortalecia o regionalismo, ao mesmo tempo em que exercia sua função designada de abastecimento das minas. Esta malha se consolidou, em seguida, com a crise da atividade mineral, em torno de zonas agropastoris mais diversificadas.

Os caminhos nas minas refletiam, então, dois tipos de fluxos, articulando diferentes níveis de realidade. Do ponto de vista local e regional, as grandes vilas eram abastecidas pelos pequenos produtores dos arredores - mas existia, simultaneamente, uma realidade em nível macro, inserida nos fluxos globais, pela qual os produtos europeus chegavam e a produção mineral era escoada (CHAVES, 1999). Tal inserção na rede global ocorria por meio das estradas inter-regionais. Na medida em que avançaram os séculos XVIII e XIX, houve uma especialização de atividades, resultado de "especificidades produtivas locais e os arranjos das rotas de comércio" (CUNHA, 2002, p.2), com "relativa independência em relação a mercados externos de outros espaços regionais do Brasil e do exterior do país" (GODOY, BARBOSA, 2008, pg.161) 


\section{HISTÓRIA}

ESTRADA DE RODAGEM SÃO PAULO-BELO HORIZONTE: FLUXOS QUE CONSTROEM UM NOVO TEMPO SOCIAL EM “A VOLTA DO MARIDO PRÓDIGO” DE GUIMARÃES ROSA Ana Maria Nogueira Rezende \& Maria Luiza Almeida Cunha de Castro

O que se construiu, então, ao longo dos anos, foi uma rede de caminhos com dupla articulação, que privilegiava ora o sentido de lugar, ora as influências globais da época, permitindo a integração, seja com a vizinhança e região, seja com as grandes cidades e portos, que atuavam como entrepostos entre o interior do país e o restante do mundo - a metrópole, a Europa e a África.

Entretanto, apesar da existência da rede de caminhos vicinais - interligada por algumas grandes vias que articulavam a capitania com suas vizinhas e com o exterior - é importante destacar a precariedade da mesma. Tais percursos, até o início do século XIX, eram esparsamente revestidos com "paus atravessados no caminho" nos trechos "muito trafegados e sujeitos a chuvas grossas" o que tornava a marcha penosa para os animais (PRADO JR., 2000, p.262). Os trajetos eram, assim, longos e árduos, impondo barreiras não só para os fluxos físicos, mas também para os fluxos cognitivos - ou seja, ideias e informações - favorecendo uma condição especial de tempo, mais lento, cristalizado.

Século XIX: a evolução no transporte rodoviário e suas contradições

No início do século XIX, já existia na capitania de Minas uma quase autonomia com relação ao abastecimento de gêneros essenciais de consumo básico, dependente apenas de importação de escravos, sal e mercadorias europeias (GODOY, 1996, BARBOSA, 2011). Com a decadência da mineração, que antes criava uma convergência para os centros produtores da região, as diferentes áreas se reorientaram e se reorganizaram a partir de suas particularidades produtivas, anteriormente construídas (CUNHA, 2002), afirmando e fortalecendo, com este processo, sua identidade. O comércio de gêneros produzidos no local, para abastecimento próprio e de outras capitais foi, então, se consolidando (BARBOSA, 2011). A população continuava a crescer e o processo de diferenciação das regiões se aprofundou. Do ponto de vista da circulação, existia uma grande capilaridade dos caminhos, os quais, embora ainda de qualidade precária, possibilitavam fluxos internos e externos - em uma capitania com produção diversificada (GODOY, 1996).

A partir da década de 1830, houve uma grande preocupação do governo provincial com obras públicas viárias - refletida em atividades de "edificação e conservação de centenas de estradas e pontes que compuseram, provavelmente, a 


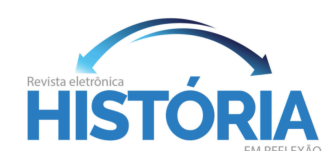

ESTRADA DE RODAGEM SÃO PAULO-BELO HORIZONTE: FLUXOS QUE CONSTROEM UM NOVO TEMPO SOCIAL EM “A VOLTA DO MARIDO PRÓDIGO” DE GUIMARÃES ROSA Ana Maria Nogueira Rezende \& Maria Luiza Almeida Cunha de Castro

mais extensa e complexa malha viária do Brasil do século XIX" (BARBOSA, 2011, p.924). Porém, esta rede continuava precária.

Libby (1988, apud CRAVO, 2013) destaca o papel paradoxal que esta precariedade teve para a economia mineira, funcionando como uma espécie de barreira protecionista, já que o custo do transporte contribuía para inviabilizar a importação. Surgiram, com isto, as primeiras experiências relativas a uma indústria de transformação - como a de tecidos caseiros utilizados pelas camadas mais pobres e as fundições (CRAVO, 2013). A dificuldade de circulação favoreceu, assim, a articulação local que, muito embora estivesse dialeticamente integrada com as vias do comércio extra regional, privilegiava um sentido de tempo permanente, contínuo (GURVITCH ${ }^{4}$, 1964, apud HARVEY, 1996), construído ao longo dos anos de colonização.

Do ponto de vista dos fluxos interprovinciais, a vinda da família real portuguesa para o Brasil reafirmou o Rio de Janeiro como eixo de mercado externo à capitania (CUNHA, 2002), o que levou a uma maior preocupação com o abastecimento da Corte a partir das regiões produtoras de alimentos (MORAIS, 2010). A abertura dos portos em 1808 também propiciou o desenvolvimento econômico nas áreas de sua influência, o que resultou em uma certa pressão para a evolução dos transportes rodoviários (RIBEIRO, 1957).

Porém, o grande investimento para a ligação interprovincial foi aplicado no transporte ferroviário, para escoamento da grande produção e exportação agrícola, principalmente cafeeira (RIBEIRO,1957; MORAIS, 2010). O modelo agroexportador esteve, portanto, estreitamente relacionado às ferrovias (GODOY, BARBOSA, 2008).

A expansão ferroviária em Minas teve início com a estrada de ferro D. Pedro II, em 1869, e restringiu-se inicialmente à zona da Mata que, em 1884, concentrava $60 \%$ da rede ferroviária brasileira. (BLASENHEIM, 1996, apud CRAVO, 2013)

\footnotetext{
${ }^{4}$ Gurvitch propõe a ideia de que formações sociais particulares estão associadas a um sentido específico de tempo. Ele classifica os tempos sociais em oito categorias. Entre eles, destacam-se o tempo permanente e o tempo alternado, que parecem caracterizar o tempo no conto: o tempo "permanente", "de longa duração e em câmara lenta", e o tempo "alternado"; de alternância entre o atraso e o avanço" (GURVITCH, 1964, apud HARVEY, 1996, p.204/205 e GURVITCH, 1969 II, p. $341 / 344$ apud FARRUGIA, 1999, p. 115, nossa tradução).
} 


\section{HISTÓRIA}

ESTRADA DE RODAGEM SÃO PAULO-BELO HORIZONTE: FLUXOS QUE CONSTROEM UM NOVO TEMPO SOCIAL EM “A VOLTA DO MARIDO PRÓDIGO” DE GUIMARÃES ROSA Ana Maria Nogueira Rezende \& Maria Luiza Almeida Cunha de Castro

Apesar da expansão posterior da rede houve uma flagrante assimetria na implantação das estradas de ferro no Brasil e grandes constrastes regionais. Em alguns espaços prevaleceram os transportes tradicionais e a circulação das demais mercadorias continuava a se fazer pelas estradas. O caráter de uma parte da economia mineira no século XIX enquadra-se, portanto, dentro de um modelo baseado, não na exportação mas, sim, em circutos mercantis internos (GODOY, BARBOSA, 2008).

Porém, apesar destas áreas não serem bem servidas pelas ferrovias em Minas, a rede se infiltrou com diferentes níveis de densidade pelo território e rompeu de forma súbita, em diversas localidades, com a dinâmica mantida pelo isolamento. Se, por um lado, este isolamento forçado era prejudicial à circulação de mercadorias numa escala ampliada, por outro, ele privilegiava as relações vicinais e inter-regionais - que continuaram a prevalecer onde a ferrovia não chegou.

Alguns autores identificam na transição brusca ocorrida com a chegada da ferrovia, a origem da crise que se constituiu na província no final do século XIX, uma vez que não houve tempo para que se operassem as transformações que colocariam a economia local em sintonia com as novas tendências produtivas. Assim, a integração da província ocorreu, por meio do modal ferroviário, "antes que a política de fortalecimento do mercado interno, sobretudo através de expedientes protecionistas, pudesse impulsionar a mudança de economia de base agrária, mas com importante setor de transformação, em economia industrial" (GODOY, BARBOSA, 2008, p.174)

No que diz respeito à matriz de transporte, um redirecionamento de foco só foi ocorrer a partir das primeiras décadas do século $\mathrm{XX}$, quando o sistema rodoviário adquiriu maior visibilidade no cenário do país, ao mesmo tempo em que se questionava a viabilidade financeira das ferrovias em determinados trajetos (GALVÃO, 2009). O frágil equilíbrio financeiro das companhias ferroviárias em operação acabou levando as instituições governamentais a reconsiderar as rodovias como alternativa de solução de integração nacional, fazendo, assim, com que elas assumissem maior importância nos planos de transporte. As décadas de 1920 e 1930 constituem, então, um momento extremamente complexo, uma encruzilhada na qual diversas tendências se colocaram em confronto, emergindo a partir de forças 


\section{HISTÓRIA}

ESTRADA DE RODAGEM SÃO PAULO-BELO HORIZONTE: FLUXOS QUE CONSTROEM UM NOVO TEMPO SOCIAL EM “A VOLTA DO MARIDO PRÓDIGO” DE GUIMARÃES ROSA Ana Maria Nogueira Rezende \& Maria Luiza Almeida Cunha de Castro

conflitantes baseadas nas diferentes propostas para a definição do futuro do país: a matriz rodoviária aparecia em contraposição à matriz ferroviária, nos transportes; o modelo primário exportador, em contraposição a um modelo de crescimento interno, baseado na industrialização. Estas oposições tinham, naturalmente, seus desdobramentos políticos e sociais.

Na escala local, em Minas, a diluição do sentido de lugar, iniciada com a penetração das ferrovias no século anterior, foi aprofundada com os investimentos nas rodovias, que permitiam uma maior capilarização, uma vez que mais viáveis financeiramente. Como parte de um projeto considerado de modernização do país, as estradas passaram a exercer um papel mais relevante na integração inter-regional, atuando como pontes entre as pequenas comunidades do sertão e os grandes centros urbanos, propagadores de novas formas de vida e comportamentos.

A construção das estradas, que a partir da República se tornara responsabilidade do governo, foi fortemente impulsionada durante o governo de Washington Luís (1926-1930), que afirmava: "As estradas são semeadoras de cidades", elegendo como lema do governo federal os dizeres "Governar é abrir estradas" (MELLO, ROSSO, 2009, p.16)

Em muitas aglomerações da região do sertão em Minas, a penetração proporcionada pelas linhas férreas, completada pela capilarização trazida pelas rodovias fez com que a década de 1920 assistisse à diluição do tempo "permanente", que privilegiava as relações do lugar, construído em torno das articulações promovidas pelos caminhos e vínculos sociais locais. Este tempo foi aos poucos sendo substituído pelo tempo "alternado", consubstanciando uma dinâmica por meio da qual o "passado e o futuro competem no presente" (GURVITCH, 1964, apud HARVEY, 1996, p. 205).

O conto de Guimarães Rosa, que tem como o pano de fundo a construção da Estrada São Paulo- Belo Horizonte, do ponto de vista da cidade de Itaguara no início da década de 1930, coloca em cena, então, estas vicissitudes de uma época de transição, com todas suas contradições. 


\section{HISTÓRIA}

ESTRADA DE RODAGEM SÃO PAULO-BELO HORIZONTE: FLUXOS QUE CONSTROEM UM NOVO TEMPO SOCIAL EM “A VOLTA DO MARIDO PRÓDIGO” DE GUIMARÃES ROSA

Ana Maria Nogueira Rezende \& Maria Luiza Almeida Cunha de Castro

$\mathrm{Na}$ região próxima ao distrito de Conquista (NEVES; CUNHA, 2015-2016). (atual Itaguara), durante a época colonial, tem-se notícia de apenas três novos caminhos - criados como atalhos para caminhos já existentes. Até 1835 , estas estradas em geral não eram carroçáveis, e por elas circulavam tropas de burros. transporte local era feito por carreiros, que utilizavam as estradas internas das fazendas com carroças e carros de boi (NEVES; CUNHA, 2015-2016). Um primeiro plano viário do governo possibilitou que algumas destas vias começassem a ser preparadas para serem carroçáveis em toda sua extensão, na região do distrito em questão. As cidades mais próximas nas quais estas melhorias foram implantadas foram Tamanduá, atual Itapecerica, e Congonhas. Porém, apesar dos esforços, as estradas continuavam extremamente precárias em épocas de chuvas (PIMENTA, 1971). Em 1871, um novo plano viário para melhoria de estradas e sua transformação em carroçáveis beneficiou, entre outras, a estrada de São João del-Rei até Oliveira e a estrada de São Gonçalo da Ponte (atual Belo Vale) até Bonfim, indo ao Pará (rio navegável- afluente do São Francisco), Pitangui e Dores do Indaiá.

\footnotetext{
Esta estrada interligaria definitivamente o distrito de Conquista ao plano rodoviário e diminuiria os dias de viagem a importantes centros consumidores, o que possibilitava a intensificação das produções agrícolas e perspectivas de lucros aos fazendeiros (PIMENTA, 1971, p.85-86).
}

No final do século XIX, as estradas ainda eram o problema maior da província e havia uma preocupação em articular os modais: as estradas carroçáveis, o sistema fluvial e as ferrovias que começavam surgir (PIMENTA, 1971, p.78). No que diz respeito à construção de ferrovias, esta incluía as linhas principais e ramais. Os mais próximos da região de Conquista chegavam às cidades de Tamanduá (atual Itapecerica), Oliveira e a estação de Entre Rios e São João del-Rei (PIMENTA, 1971). O distrito de Conquista, entretanto, ainda não era diretamente atendido e, nas décadas de 1910 e 1920, a circulação era predominantemente feita por animais e carros de boi - além de alguns poucos automóveis que chegaram com dificuldade à cidade.

No início do século $X X$, a passagem de uma economia essencialmente agrícola para uma economia industrial, processo iniciado em São Paulo, influenciou as políticas de transporte do estado e, em seguida, as políticas federais. A articulação 


\section{HISTÓRIA}

ESTRADA DE RODAGEM SÃO PAULO-BELO HORIZONTE: FLUXOS QUE CONSTROEM UM NOVO TEMPO SOCIAL EM “A VOLTA DO MARIDO PRÓDIGO” DE GUIMARÃES ROSA

Ana Maria Nogueira Rezende \& Maria Luiza Almeida Cunha de Castro

entre os diversos pontos do território foi, então resultado, de uma estratégia para integração entre a atividade industrial e as atividades da cadeia produtiva (GODOY, 1996). São Paulo, que a partir do ciclo de exploração do café tinha não somente conquistado a hegemonia econômica nacional mas, também, assistido à substituição do trabalho escravo pelo assalariado e ao fortalecimento de um mercado nacional (SCHIFFER,1999), transformara-se em um importante polo econômico, de forma que sua conexão com a nova capital do estado de Minas Gerais era imprescindível para a evolução deste último.

A Estrada São Paulo-Belo Horizonte partiu, então, de uma necessidade de integração entre a atividade industrial e as atividades da cadeia produtiva e conectou São Paulo a um interior de país que havia evoluído de forma independente conservando ainda as características conferidas por este isolamento. A ligação foi projetada e sua construção foi realizada entre os anos de 1928 e 1934 - com atrasos. A rodovia original seguia de São Paulo até Belo Horizonte passando por cidades como Atibaia, Bragança, Manducaya, Cambuy, Pouso Alegre, São Gonçalo, Lavras, e ainda Itaguara, Crucilândia, Bonfim, Ibirité -Sarzedo, Brumadinho, Contagem, e pela região onde hoje se encontra o bairro do Barreiro (na época, fazenda do Barreiro) (ARQUIVO..., 1927-1934) (ver mapa 1). 


\section{HISTÓRIA}

ESTRADA DE RODAGEM SÃO PAULO-BELO HORIZONTE: FLUXOS QUE CONSTROEM UM NOVO TEMPO SOCIAL EM “A VOLTA DO MARIDO PRÓDIGO” DE GUIMARÃES ROSA

Ana Maria Nogueira Rezende \& Maria Luiza Almeida Cunha de Castro

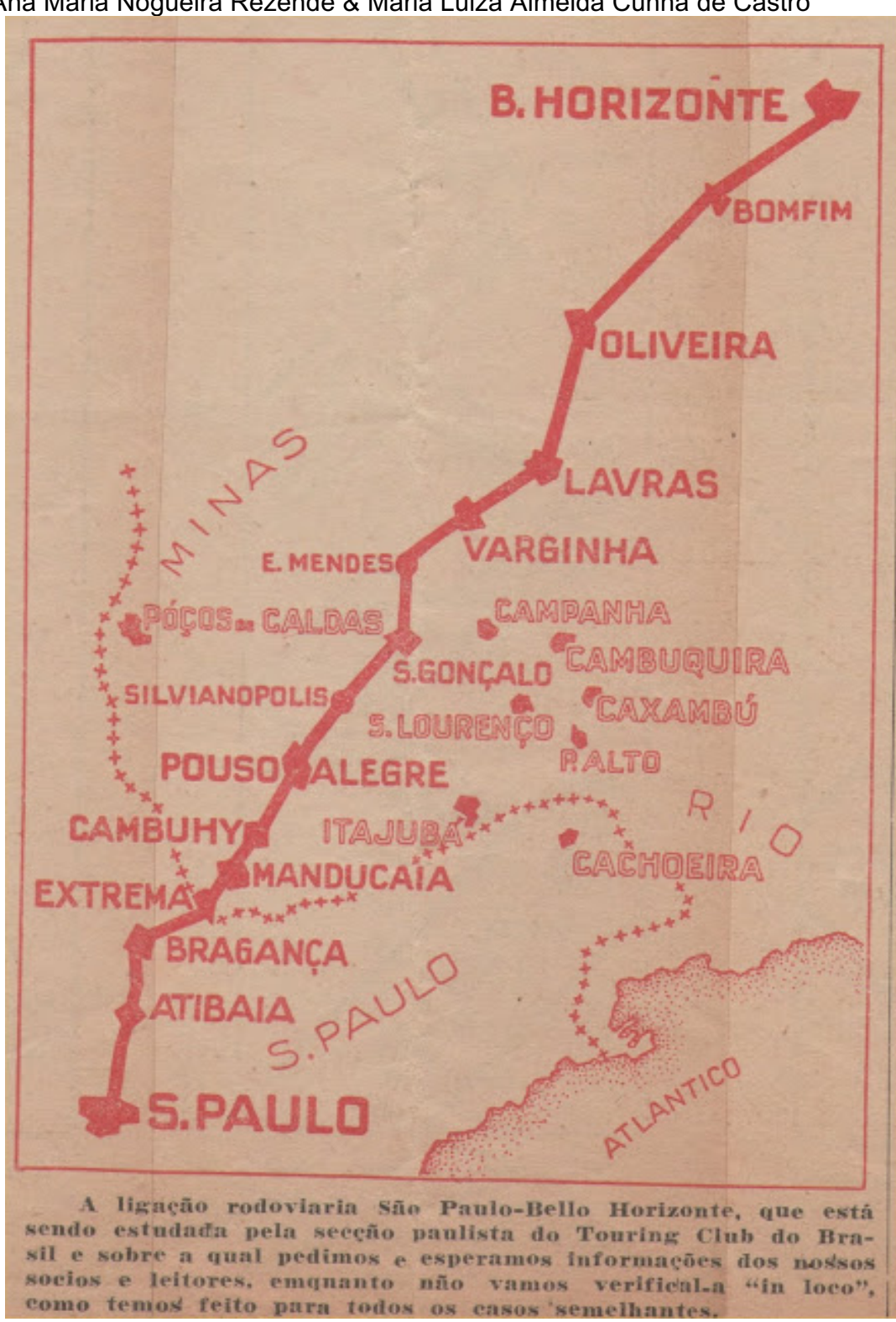

Mapa 1. Traçado da ligação rodoviário SP-BH (CORREIO..., 1935? apud GIESBRECHT, 2016)

O Secretário de Agricultura, Viação e Obras Públicas, Djalma Pinheiro Chagas (1884-1962), foi responsável pela autorização da construção da Estrada de Rodagem no trecho de Japão - distrito pertencente a Oliveira/ atual cidade de Carmópolis de Minas - até Bonfim (ARQUIVO..., 1929). O ponto de partida era a atual ponte do Rio Pará passando pela cidade e tomando o rumo do município de Dom Silvério (Atual Crucilândia) 


\section{HISTÓRIA}

ESTRADA DE RODAGEM SÃO PAULO-BELO HORIZONTE: FLUXOS QUE CONSTROEM UM NOVO TEMPO SOCIAL EM “A VOLTA DO MARIDO PRÓDIGO” DE GUIMARÃES ROSA Ana Maria Nogueira Rezende \& Maria Luiza Almeida Cunha de Castro

A empresa de construtores A.R Gianetti \& Almeida Magalhães foi contratada para fazer o serviço de $68.000 \mathrm{~m}^{3}$ neste trecho, e para o serviço de desmonte entre as estacas de Dom Silvério $n^{\circ} 800$, até estaca $n^{\circ} 520$ em Burnier (ARQUIVO..., 1929). Documentos levantados no Arquivo Público Mineiro - (ARQUIVO..., 1929) identificam o contrato de execução do trecho firmado com esta empresa, de propriedade de Américo René Gianetti - mais tarde prefeito de Belo Horizonte (1951-1954).

Novos fluxos e novas conexões: o fim do isolamento do sertão

A origem de Itaguara está na passagem de Lourenço Castanho Taques, o velho, por Minas Gerais, em expedição bandeirista que saiu do norte da Vila de São Paulo, em 1668. Em combate com as tribos indígenas que habitavam a região Guaianases - Taques promoveu o seu massacre (NEVES; CUNHA, 2015-2016) e iniciou uma aglomeração às margens do Ribeirão Conquista, (conhecido até 1755 como Ribeirão São Fellipe). Este foi um dos primeiros arraiais de Minas Gerais e levou, então, o nome de Arraial de Conquista (VASCONCELOS, 1974).

O desenvolvimento local esteve ligado à economia da mineração, dentro de uma dinâmica tão intensa quanto aquela da "economia urbana que a gerou, oriunda do aprofundamento da divisão socio-espacial do trabalho implícita ao necessário abastecimento daquela forte e setorizada economia" (MONTE-MÓR, 2001). A rentabilidade em potencial da atividade mineradora fez com que se concentrassem nela os investimentos, em detrimento da economia de subsistência na própria região. A necessidade de abastecimento criou mercados que viabilizaram as atividades, como as de agricultura e transporte, em localidades próximas. (MONTE-MÓR, 2001).

A região de Conquista foi, então, inicialmente centro de agricultura e pecuária, abastecendo as zonas de mineração à época das Bandeiras (ENCICLOPÉDIA..., 1959) Localizada em posição estratégica, sua conexão com diversos caminhos tradicionais permitiu seu fortalecimento como centro fornecedor de produtos agrários na região e possibilitou que se articulasse dentro de uma rede de exploração econômica na província - dominada por determinadas famílias poderosas - que incluía a atividade mineradora e grandes fazendas (NEVES; CUNHA, 2015-2016). Suas atividades principais continuaram ligadas à agricultura e à criação de animais. No início do século XIX, os produtos principais incluíam gêneros de subsistência, cana 


\section{HISTÓRIA}

ESTRADA DE RODAGEM SÃO PAULO-BELO HORIZONTE: FLUXOS QUE CONSTROEM UM NOVO TEMPO SOCIAL EM “A VOLTA DO MARIDO PRÓDIGO” DE GUIMARÃES ROSA Ana Maria Nogueira Rezende \& Maria Luiza Almeida Cunha de Castro

de açúcar, tabaco, criação de suínos e algum gado bovino. Por volta da década de 1820, intensificou-se o plantio do tabaco e teve início o do algodão (NEVES; CUNHA, 2015-2016). O Distrito com a denominação de Nossa Senhora das Dores da Conquista foi criado no final do século XIX, subordinado ao município de Bonfim (Lei provincial $n^{\circ} 1667$, de 14 ou 16-09-1870, e Lei estadual $n^{\circ} 2$, de 14-09-1891). Já em 1901, foi transferido do município de Bonfim, para então constituir o novo município de Itaúna (Lei estadual $n^{\circ} 319$, de 16-09-1901).

No final do século XIX, a chegada da ferrovia e a melhoria de algumas estradas em Minas beneficiaram outras áreas vizinhas, aumentando a concorrência, mas também os mercados, propiciando uma certa prosperidade, reforçada pela transferência do centro político para a vizinha Belo Horizonte, no início do século XX.

Em 1923, sob influência do movimento Indianista, o Distrito de Dores da Conquista foi rebatizado como Itaguara - ainda pertencendo ao município de Itaúna, do qual só veio a se emancipar em 1943 (NOGUEIRA, 2011; ENCICLOPEDIA, 1959; ROSA, 2014). A passagem da estrada São Paulo - Belo Horizonte dentro do distrito, foi um dos fatores que o integraram em uma dinâmica econômica mais ampla e acabaram por levar a sua emancipação como cidade (NEVES; CUNHA, 2015-2016).

\section{A volta do Marido pródigo}

O conto de Guimarães Rosa "A volta do marido pródigo" tem como cenário a construção desta estrada, em Itaguara. O enredo trata da história de Lalino Salãthiel, um mulato que trabalha nas obras da futura rodovia, sob a supervisão do Sr. Marra. Um determinado dia, o mulato resolve ir para o Rio de Janeiro em busca de aventuras e pede financiamento ao espanhol Ramiro, que está interessado em sua mulher. Ramiro disponibiliza os recursos necessários, para ter caminho livre para sua conquista amorosa e Lalino parte, sem remorsos. Seis meses depois, gasto o dinheiro, ele retorna e, aos poucos, reconquista a confiança de todos na cidade, inclusive de um político em campanha, o Major Anacleto, para quem passa a trabalhar. Utilizando ardis diversos, ele termina por reconquistar também a esposa e fazer expulsar os espanhóis. 


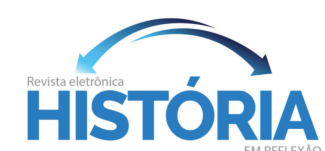

ESTRADA DE RODAGEM SÃO PAULO-BELO HORIZONTE: FLUXOS QUE CONSTROEM UM NOVO TEMPO SOCIAL EM “A VOLTA DO MARIDO PRÓDIGO” DE GUIMARÃES ROSA Ana Maria Nogueira Rezende \& Maria Luiza Almeida Cunha de Castro

O conto retrata uma época em que Itaguara era, portanto, representativa dos modos de vida do sertão, e ao mesmo tempo da organização sociopolítica do período histórico da Primeira Republica. Emergem, então, questões como o apadrinhamento, a violência, as arbitrariedades, os "costumes tradicionais e patriarcais", legados das contradições do período colonial - e ainda "a ruptura com o velho ou assimilação do novo sob o controle da tradição" (RONCARI, 2004, p. 21).

Embora o distrito fosse articulado pelos caminhos tradicionais, o contato com os grandes centros e sua dinâmica ainda era permeado por trajetos complicados sem acesso à ferrovia ou trechos de rodovia - o que fazia com que as cidades distantes figurassem como sonhos no imaginário local. "Não estando em proximidade às rotas comerciais mais movimentadas, Itaguara conservava em si largas características da vida do século $X I X$, das práticas tropeiras e dos resquícios das atividades tradicionais" (NEVES; CUNHA, 2015-2016, p.13).

Assim, no conto, as cidades de Belo Horizonte e Rio de Janeiro aparecem idealizadas: Lalino explora este imaginário ao entreter seus companheiros com histórias inventadas. As ideias vêm por meio de imagens trazidas em revistas imagens de mulheres europeias, revelando o fetiche com as estrangeiras de olho azul - que reverberam no imaginário dos homens, captando sua atenção e seduzindo-os.

Quando resolve partir, Lalino troca a esposa - Maria Rita - pelo sonho idealizado: "E na revista de cinema havia uma deusa loira, com lindos pés desnudos, e uma outra, morena, com muita pose e roupa pouca; e Maria Rita perdeu" (ROSA, 1980, p.80).

Antes de se mudar, o mulato anuncia, ainda incerto, ele mesmo, quanto à cidade de destino: "vou ser tocador de bonde, no Rio de Janeiro" (ROSA, 1980, p.64). e “Vou p'ra o Belorizonte... Arranjeizinho lá um lugar de guarda-civil..."(p.63).

Os protagonistas que Rosa apresenta correspondem a figuras reais, contemporâneos da época em que atuou como médico na cidade. Conforme pesquisas no acervo da Biblioteca Municipal João Guimarães Rosa, Waldemar (o encarregado da obra) e José Benjamim Marra - seu Marra, trabalharam efetivamente na construção da estrada, chefiados por Paschoal Torquette, na empresa A.R. Gianetti \& Almeida Magalhães, responsável pelo trecho do Rio Pará (na divisa dos 
ESTRADA DE RODAGEM SÃO PAULO-BELO HORIZONTE: FLUXOS QUE CONSTROEM UM NOVO TEMPO SOCIAL EM “A VOLTA DO MARIDO PRÓDIGO” DE GUIMARÃES ROSA

Ana Maria Nogueira Rezende \& Maria Luiza Almeida Cunha de Castro

atuais municípios de Carmópolis de Minas- antes distrito de Japão - Cláudio e Itaguara até a cidade de Bonfim).

O personagem principal, Lalino Salãthiel, teria sido um empregado na construção da estrada em Itaguara, na turma de trabalho do sr. Paschoal Torquette (NEVES; CUNHA, 2015-2016). Durante sua permanência em Itaguara, Rosa teria mantido amizade com o Sr. Marra que, além de trabalhar na construção da estrada se envolveu efetivamente em projetos de teatro na cidade, tal como no conto. Por sua vez, o Major Anacleto, político para quem Lalino passa a trabalhar quando retorna do Rio, seria o major Antônio Luiz de Oliveira, chefe político local da época.

Deste modo, a descrição que o autor faz da construção da estrada é, sem dúvida, resultado de uma observação participativa: quando morador da cidade, ele se distraia por horas a fio a conversar com os ciganos que se ajuntavam nos empréstimos (escavações à margem das estradas para obtenção de terra para os aterros) da rodovia que se constrói: Chilenos, húngaros e sérvios que já usam o Ford-29. Aliás, os passeios na rodagem, por aterros e desaterros pareciam ser a distração de todos, assustados com a perspectiva e mudanças.

Os relatos dos detalhes do serviço ilustram com clareza a precariedade tecnológica: era a engenharia usada naquele tempo, naquele lugar.

No corte, a turma do seu Marra bate rijo, de picareta, atacando no paredão pedrento a brutalidade cinzenta do gneiss. Bom trecho, pois, remunerador. Acolá, a turma dos espanhóis cavouca terra mole, xisto talcoso e micaxisto; e o chefe Garcia está irritado, porque, por causa disso, vão receber menos, por metro quadrado e metro cúbico. Adiante, uns homens colocando os paus do mata-burro. Essa outra gente, à beira, nada tem conosco: serviço particular de seu Remígio, dono das terras, que achou e está explorando uma jazida de amianto. $\mathrm{E}$, mais adiante, o pessoal do Ludugéro, acabando de armar as longarinas da ponte (ROSA, 1980, p.70).

Rosa (1980) retrata o canteiro de obra, o trabalho que não para, a continuidade que dilui o tempo... O trabalho animal se confunde com o humano: "Patas em marcha matemática, andar consciencioso e macio, ele chega, de macio, ele chega, de sobremão"(p.69). Dois burros fazem o transporte do material de corte para utilização no leito da estrada:

É um burrinho, que vem sozinho, puxando o carroção (...) O preto desaferrolha o taipal da traseira, e a terra vai caindo para o barranco. 


\section{HISTÓRIA}

ESTRADA DE RODAGEM SÃO PAULO-BELO HORIZONTE: FLUXOS QUE CONSTROEM UM NOVO TEMPO SOCIAL EM “A VOLTA DO MARIDO PRÓDIGO” DE GUIMARÃES ROSA

Ana Maria Nogueira Rezende \& Maria Luiza Almeida Cunha de Castro

Os outros ajudam, com as pás. (...). No meio do caminho, cruza-se com o burro pêlo-de-rato, que vem com o outro carroção. É o décimo terceiro encontro, hoje, e como ainda irão passar um pelo outro, sem falta, umas três vezes esse tanto - do aterro ao corte, do corte ao aterro- não se cumprimentam. (ROSA, 1980, p.55).

A descrição pitoresca retrata as estradas abertas na enxada, conforme a prática da época, pela qual, como no século anterior, empregava-se pás, machados, foices, alavancas, brocas, martelos, serrotes, marrões e picos, dentre outras ferramentas (CRAVO, 2013). As técnicas aplicadas na construção não parecem ter se desenvolvido muito desde o século XIX - Rosa descreve o trabalho dos profissionais não qualificados, responsáveis por tarefas tradicionalmente executadas para obras tais como as que descreve Cravo no século XIX "derrubada e roçada da estrada, o arrancar de tocos e raízes; os trabalhos na pedreira, a edificação do leito, a cozinha, a construção de pontes, canais e socalcos e a abertura de caminhos laterais para a retirada e madeira e pedra" (CRAVO, 2013,p.11)

No processo de difusão tecnológica aplicado à construção de estradas e pontes ao longo deste período, destaca-se a importância do diálogo teoria x prática. Assim, a obra é resultado não somente dos cuidadosos projetos elaborados pelos engenheiros da época, que buscam conhecimentos inclusive em outros países (CRAVO, 2013), mas também das intervenções feitas a partir do "saber fazer", que impõe adaptações e modificações frequentes. Esta característica determina a singularidade de cada construção, que se desenvolve de acordo com condições do meio

Apesar da tecnologia de construção ser ainda tradicional, os novos fluxos que a estrada configura são essencialmente transformadores: eles alteram o modelo que vinha prevalecendo até então, no qual as estradas de rodagem cumpriam um papel de articulação local, e às ferrovias cabia fazer as ligações que envolviam grandes distâncias (TAVARES, 2014). Assim, a construção da estrada São Paulo - Belo Horizonte promove uma ligação interestadual que transforma Itaguara e as relações mantidas neste espaço. A nova rodovia possibilita a articulação com diversas localidades e com as capitais - priorizando estes novos vínculos em detrimento dos vínculos tradicionais com o Vale do Rio Paraopeba, que continua com as estradas em péssimo estado (NEVES; CUNHA, 2015-2016). 


\section{HISTÓRIA}

ESTRADA DE RODAGEM SÃO PAULO-BELO HORIZONTE: FLUXOS QUE CONSTROEM UM NOVO TEMPO SOCIAL EM “A VOLTA DO MARIDO PRÓDIGO” DE GUIMARÃES ROSA Ana Maria Nogueira Rezende \& Maria Luiza Almeida Cunha de Castro

O conto de Rosa deixa entrever esta tensão latente entre o tempo e o lugar. $O$ enredo trata do lugar agreste, rústico, este pedaço de sertão que se afirma, com sua ordem estabelecida, seus costumes, sua estabilidade. Tudo volta a se acomodar, mesmo se eventos externos provocam perturbações: Lalino deixa a cidade e é censurado por todos - mas retorna e recupera sua posição social, sua esposa, seus amigos. A força do lugar prevalece e tudo se organiza como antes, dentro de uma lógica de tempo "permanente".

Por outro lado, o pano de fundo de suas aventuras revela tensões sutis, subjacentes - os ciganos, os espanhóis, o trabalho da estrada são apenas o anúncio da grande perturbação que está por vir, dos novos fluxos que vão aos poucos se materializar. São as evidências de uma realidade nova que se infiltra, trazendo as características de um outro tempo - o tempo alternado de Gurvitch (1964, apud HARVEY, 1996), que "hesita entre o atraso e o avanço” (Farrugia, 1999 , p. 115), transição para o moderno, ao qual o lugarejo vai ter que se ajustar: o tempo da indústria, da vida urbana, das relações impessoais. São novos desafios e estímulos, que vão mudar o sentido de lugar, que caracteriza Itaguara, ainda isolada das grandes cidades.

Assim, ao mesmo tempo que a narrativa traz uma perspectiva universalizante (o sertão como expressão do mundo, os personagens construídos "como um tipo e não como um caráter" (RONCARI, 2004, p. 32), a perspectiva sociohistórica aparece com bastante clareza como uma das camadas de construção da narrativa (RONCARI, 2004). O autor cria, então, "uma vivência poderosamente nossa e ao mesmo tempo universal, que valoriza e eleva a nossa arte" (CANDIDO apud NASCIMENTO,2010, p. 24)

Lalino representa o sertanejo, criado no interior do estado, e "os seus antepassados talvez tivesse sido sertanejos ocupados na criação do gado ou na agricultura de subsistência" (RONCARI, 2004 p. 39). A construção da estrada vai proporcionar novas experiências, transformar o caráter do sertão, subverter significados, e mudar as histórias do dia a dia - ela define o início de uma transmutação que vai fazer desaparecer o Lalino, o seu Marra, o Major Anacleto. Em breve, os moradores locais vão partir para as capitais em busca de trabalho na indústria. Os que ficarem, não vão ser mais os mesmos - Itaguara vai se articular à 


\section{HISTÓRIA}

ESTRADA DE RODAGEM SÃO PAULO-BELO HORIZONTE: FLUXOS QUE CONSTROEM UM NOVO TEMPO SOCIAL EM “A VOLTA DO MARIDO PRÓDIGO” DE GUIMARÃES ROSA Ana Maria Nogueira Rezende \& Maria Luiza Almeida Cunha de Castro

Região Metropolitana de Belo Horizonte: "O trecho da rodovia ficou pronto. O pessoal de fora tomou rumo, com carroções e muares, famílias e ferramentas, e bolsos cheios de apólices, procurando outras construções" (ROSA, 1980, p. 82).

Mais tarde, serão os habitantes locais que, com mais facilidade do que Lalino, ou que o pessoal de fora, vão "tomar rumo". Minas nasceu dos caminhos, dos lugares, das trocas - mas o caráter das trocas mudou - e os caminhos serão agora outros.

Considerações finais

$\mathrm{Na}$ região da Capitania de Minas a formação de aglomerações e o estabelecimento de atividades econômicas materializou-se a partir da definição de caminhos e estradas, de forma a proporcionar fluxos que resultavam em descobertas, novas relações e trocas, encontros, permanências e identidades.

Ao longo do período de colonização, frente a uma especialização das atividades, houve uma dupla articulação destes fluxos, que gerou especificidades na organização econômica e social. A ligação com as vias inter-regionais movimentou uma economia exportadora, principalmente de minerais, por onde também transitavam viajantes, aventureiros, escravos, e outros. Já circunscrita à região, organizou-se uma economia de abastecimento, por meio de uma rede de caminhos que garantia a ligação entre áreas produtoras e consumidoras. A partir do século XIX, esta rede baseada na produção de alimentos foi consolidada- embora ainda em condições estruturais insatisfatórias. Ao mesmo tempo, foram renovados os fluxos com o mercado internacional, agora mobilizados em torno da exportação do café. Em detrimento dos investimentos em rodovias, o modal de transporte ferroviário, na época, foi escolhido para os investimentos, permitindo uma penetração no interior especialmente na zona da Mata Mineira. As demais regiões permaneceram bastante isoladas - prejuízo e vantagem - que levava a limitações econômicas, mas que privilegiava e preservava as relações locais e regionais - até o início do século XX.

O conto de Guimarães Rosa descreve o momento da transição, no qual esta estrutura duplamente articulada, que se manteve desde a época colonial, estava prestes a ser rompida: a construção da nova estrada significa não apenas a ligação entre os dois importantes centros - São Paulo e Belo Horizonte - mas anuncia, por 


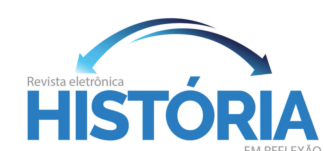

ESTRADA DE RODAGEM SÃO PAULO-BELO HORIZONTE: FLUXOS QUE CONSTROEM UM NOVO TEMPO SOCIAL EM “A VOLTA DO MARIDO PRÓDIGO” DE GUIMARÃES ROSA Ana Maria Nogueira Rezende \& Maria Luiza Almeida Cunha de Castro

onde passa, o fim do isolamento do sertão e sua incorporação aos fluxos inter e extra regionais, dentro de uma dinâmica de globalização.

Em um processo multifacetado, o resultado não se reflete apenas em estados econômicos, mas revela uma mudança do indivíduo sertanejo, em face do conflito ativo e crescente entre o tempo e o lugar. Este conflito se caracteriza por uma relação dialética na configuração da sociedade que emerge, a partir das tensões sociais e culturais do processo de homogeneização possibilitado pelos novos fluxos, que se contrapõe à força da afirmação do caráter local. Tais transformações anunciam a fluidez dos tempos, abrindo espaço para o surgimento de "novos sertões", com outras articulações.

\section{Referências}

APPADURAI, Arjun. Disjuntura e diferença na economia cultural global. In: Dimensões culturais da globalização: A modernidade sem peias. Lisboa: Teorema, 2004.

ARQUIVO PÚBLICO MINEIRO; Secretaria de Agricultura, Viação e Obras Públicas, série 4.5, cx. 65, pc. 01, 1927-1934. SA 252-254.

BARBOSA, Lidiany Silva. Os provedores da técnica: os engenheiros provinciais e a edificação da infraestrutura viária de Minas Gerais. História, Ciências, Saúde Manguinhos. Rio de Janeiro: v.18, n.3, jul-set. 2011, p.907-928.

BLOCH, Pedro. Depoimento de Guimarães Rosa sobre a indicação à Academia Brasileira de Letras. Rio de Janeiro: Bloch Editores, 1963 (Entrevista). Transcrição apresentada na Revista Manchete $n^{\circ}$ 580, de 15 jun. 1963.

CHAVES, Cláudia M.G.. Perfeitos negociantes: mercadores das minas setecentistas. Belo Horizonte: Annablume Editora/ Unicentro Newton Paiva, 1999.

CRAVO Télio A.. Engenharia, engenheiros e o universo da difusão de tecnologia no Brasil Imperial: patente, projeto e construção de uma ponte lattice em Minas Gerais (1860-1864). Revista Brasileira de História da Ciência. Rio de Janeiro: v. 5, n. 2, p. 354-368, jul. - dez. 2012, p. 365.

CRAVO, Télio A.. Pontes e estradas em uma província no interior do Brasil oitocentista: engenharia, engenheiros e trabalhadores no universo construtivo da infraestrutura viária de Minas Gerais (1835-1889). 2013. Dissertação (Mestrado). Universidade de São Paulo, São Paulo, 2013

CRUZ, Cícero F.. Arquitetura Rural no Sul de Minas nos séculos XVIII e XIX. Dissertação (Mestrado em Arquitetura e Urbanismo). Universidade de São Paulo,, São Carlos, 2008. 


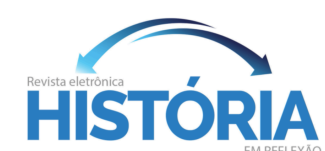

ESTRADA DE RODAGEM SÃO PAULO-BELO HORIZONTE: FLUXOS QUE CONSTROEM UM NOVO TEMPO SOCIAL EM “A VOLTA DO MARIDO PRÓDIGO” DE GUIMARÃES ROSA Ana Maria Nogueira Rezende \& Maria Luiza Almeida Cunha de Castro

CUNHA, Alexandre M.. A diferenciação dos espaços: um esboço de regionalização para o território mineiro no século XVIII e algumas considerações sobre o redesenho dos espaços econômicos na virada do século. In: $X$ SEMINÁRIO SOBRE $A$ ECONOMIA MINEIRA - CEDEPLAR/UFMG, 2002, Diamantina. Anais... Belo Horizonte: CEDEPLAR/UFMF, 2002.

ENCICLOPÉDIA DOS MUNICÍPIOS BRASILEIROS, volume XXV, 1959. Biblioteca do Instituto Brasileiro de Geografia e Estatística - IBGE. Disponível em:

http://biblioteca.ibge.gov.br/visualizacao/dtbs/minasgerais/itaguara.pdf

Enciclopédia dos Municípios Brasileiros. Volume XXV, 1959. Biblioteca do Instituto Brasileiro de Geografia e Estatística - IBGE. Disponível em:

http://biblioteca.ibge.gov.br/visualizacao/dtbs/minasgerais/itauna.pdf

FARRUGIA, F. une brève histoire des temps sociaux: Durkheim, Halbwachs, Gurvitch. Cahiers Internationaux De Sociologie, 106, 95-117. Disponível em http://www.jstor.org/stable/40690808

GALVÃO, Olímpio J de Arroxelas. Desenvolvimento dos transportes e integração regional no Brasil-uma perspectiva histórica. Planejamento e políticas públicas, n. 13, 2009.

GIESBRECHT, Ralph. As estradas Paulistas dos anos 1930, 13 jan. 2016.

Disponível em: http://blogdogiesbrecht.blogspot.com.br/2016/01/as-estradaspaulistas-dos-anos-1930.html

GODOY, Marcelo Magalhães. Intrépidos viajantes e a construção do espaço: uma proposta de regionalização para as Minas Gerais do século XIX. Belo Horizonte: CEDEPLAR/ UFMG, 1996. (Texto para discussão, n. 109).

GODOY, Marcelo Magalhães; BARBOSA, Lidiany Silva. Uma outra modernização: transportes em uma província não-exportadora - Minas Gerais, 1850-1870.

Economia e Sociedade. Campinas: v.17, n. 2 (33), 2008, pg.161.

HARVEY, David. A Condição Pós-Moderna : uma pesquisa sobre as origens da mudança cultural . 6 ed. São Paulo: Loyola, 1996

LEONEL, Maria Célia de Morais. Grande sertão: veredas: alguns neologismos semânticos. ALFA: Revista de Linguística, v. 41, 1997.

MAIA, João Roberto. Sobre a crítica de Guimarães Rosa. Espéculo, n. 37,s.p., 2007. Disponivel em: http://www.ucm.es/info/especulo/numero37/guimaro.html

MELLO, Mauro Pereira de; ROSSO, Silvana. Governar é abrir estradas: $O$ concreto pavimentando caminhos na formação de um novo país. São Paulo: Journey Comunicações Ltda., $1^{\text {a }}$ ed, 2009, p.16. Disponível em:

http://viasconcretas.com.br/wpcontent/uploads/2013/02/Livro Governar Abrir Estradas OK.pdf

MONTE-MÓR, Roberto Luís de Melo. Gênese e estrutura da cidade mineradora. Belo Horizonte: CEDEPLAR/FACE/UFMG, 2001. (Texto para Discussão n. 164).

MORAIS, Viviane Alves de. Estradas Interprovinciais no Brasil Central: Mato Grosso, Goiás, Minas Gerais (1834-1870). Dissertação (Mestrado). Universidade de São Paulo, São Paulo, 2010 


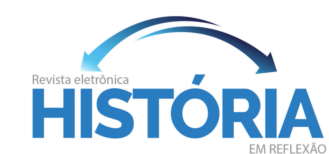

ESTRADA DE RODAGEM SÃO PAULO-BELO HORIZONTE: FLUXOS QUE CONSTROEM UM NOVO TEMPO SOCIAL EM “A VOLTA DO MARIDO PRÓDIGO” DE GUIMARÃES ROSA Ana Maria Nogueira Rezende \& Maria Luiza Almeida Cunha de Castro

NASCIMENTO, Maria Ana Bernardo do. Análise intertextual do conto "A volta do marido pródigo”, de Guimarães Rosa, com a parábola O filho pródigo. 2010. 122 f. Dissertação (mestrado) - Universidade Estadual Paulista, Faculdade de Ciências e Letras de Assis, 2010. Disponível em: <http://hdl.handle.net/11449/94070>.

NEVES, Marcos Vinícius Duque; CUNHA, Sandro Giovanni M. Guimarães Rosa em Itaguara. Dossiê Acervo MUSA. Prefeitura de Itaguara: 2015-2016.

NOGUEIRA, Guaracy de Castro. Artigo História de Itaguara. 2011.

PESAVENTO, Sandra Jatahy et al. História \& literatura: uma velha-nova história.

Nuevo mundo mundos nuevos, n. 6-2006, 2006.

PIMENTA, Demerval José. Caminhos de Minas gerais. Belo Horizonte: Imprensa Oficial, 1971.

PRADO JR., Caio. Formação do Brasil Contemporâneo. São Paulo: Editora Brasiliense, [1942] 2000, p.262.

RIBEIRO, Paulo de Assis. Estrutura, Economia e política de transportes. Revista dos tribunais. São Paulo, 1957.

RICOEUR, Paul. Time and narrative. University of Chicago Press, 2010

RONCARI, Luiz. O Brasil de Rosa: mito e história no universo rosiano: o amor e o poder. SciELO-Editora UNESP, 2004.

ROSA, Fleury. Itaguara: Um passado de glórias, um futuro de conquistas. Cidades.

Revista Viva Grande BH. Edição 11 de 27 jun. 2014. Disponível em:

http://www.vivagrandebh.com.br/materia/itaguara-um-passado-de-glorias-um-futurode-conquistas

ROSA, João Guimarães. Sagarana. Rio de Janeiro: José Olympio, 1980, 23ª edição,

SCHIFFER, Sueli Ramos. São Paulo como polo dominante do mercado unificado nacional. In: DEÁK, Csaba; SCHIFFER, Sueli Ramos. O processo de urbanização no Brasil. São Paulo: EDUSP, 1999.

TAVARES, Jefferson Cristiano. A infraestrutura rodoviária na urbanização do território paulista: as escalas de integração da cadeia produtiva, 1913-1944.

Paranoá n. 13, p. 93-100, 2014.

VASCONCELOS, Diogo. História antiga das Minas Gerais. Belo Horizonte: Itatiaia, 1974. 